\title{
A comparison of BASIC language timing loops for the TRS-80 microcomputer
}

\author{
THOMAS BIDDLE PERERA \\ Montclair State College, Upper Montclair, New Jersey 07043
}

\begin{abstract}
For users who wish to program the TRS-80 microcomputer exclusively in BASIC, the FORNEXT timing loop provides almost twice as fine temporal resolution as the incrementing loop. A temporal resolution of $6.62 \mathrm{msec}$ is possible with the FOR-NEXT loop.
\end{abstract}

Since the TRS-80 has no accessible hardware clock, the timing of events must be performed by a software clock. An excellent machine-language software timing program with millisecond resolution has been written by Owings and Fielder (1979). For users who do not need millisecond resolution or who want all programming in BASIC, it is useful to know the relative resolution that can be obtained with various BASIC timing loops. The following timing loops are provided for comparison, and the time resolution of each loop is indicated:

Program 1:

$\begin{array}{ll}10 & \mathrm{~K}=0 \\ 20 & \mathrm{~K}=\mathrm{K}+1 \\ 30 & \mathrm{~A} \$=\mathrm{INKEY} \$ \\ 40 & \mathrm{IF} \text { A } \$=\text { "“" THEN GOTO } 20 \\ 50 & \text { PRINT K/81; "SEC" }\end{array}$

This program completes 81 iterations in $1 \mathrm{sec}$. The resolution is therefore $12.3 \mathrm{msec}$.

Program 2:

$\begin{aligned} 10 & \text { FOR K=0 to } 10000 \\ 20 & \text { A } \$=I N K E Y \$ \\ 30 & \text { IF A } \$=" 1 \text { " THEN } 100 \\ 40 & \text { NEXT K } \\ 100 & \text { PRINT K/105; "SEC" }\end{aligned}$

This program completes 105 iterations in $1 \mathrm{sec}$. The resolution is therefore $9.5 \mathrm{msec}$.

Program 3:

$\begin{aligned} 10 & \text { FOR K=0 to } 1000 \\ 20 & \text { IF INKEY } \$=" 1 \text { " THEN } 100 \\ 30 & \text { NEXT K } \\ 100 & \text { PRINT K/151; “SEC" }\end{aligned}$

This program completes 151 iterations in $1 \mathrm{sec}$. The resolution is therefore $6.62 \mathrm{msec}$. This program may be modified to sample several keys at a minimal loss of resolution and is probably the most satisfactory if keyboard Keys $1-9$ can be used as response keys.

Changing Line 20 to read: 20 ON VAL(INKEY\$) GOTO 100,200 results in 142 iterations in $1 \mathrm{sec}$, for a resolution of $7.0 \mathrm{msec}$. With three alternative GOTO lines, the resolution becomes $7.7 \mathrm{msec}$. Four alternative GOTO lines reduce the resolution to $8.7 \mathrm{msec}$.

For users who do not need the $1-\mathrm{msec}$ resolution provided by machine-language programs, each program can provide the latency in seconds to six significant figures by dividing the final value of $\mathrm{K}$ by the number of iterations in $1 \mathrm{sec}$, as shown in Line 100 . The exact resolution should be determined by each user for the specific TRS-80 system and program to be used. This may be done by allowing the loop to iterate for $100 \mathrm{sec}$ and then dividing $\mathrm{K}$ by 100 . The resolution of BASIC timing loops may also be doubled by doubling the frequency of the crystal clock.

An important trick for obtaining the maximum timing resolution is to initialize the timing counter variable ( $K$ in this case) and any other variables used inside the timing loop at the very beginning of the program. Use the statement $K=5$ at the start of the program. This places the variable $K$ at the top of the push-down stack of variables, making it easier for the program to find the variable and overcoming the long initial delay that occurs whenever a variable is first initialized.

\section{REFERENCES}

Owings, R. A., \& Fiedler, C. A. Measuring reaction time with millisecond accuracy using the TRS-80 microcomputer. Behavior Research Methods \& Instrumentation, 1979, 11, 589-591.

(Received for publication July 20, 1979; revision accepted August 9, 1979.) 